\title{
Lecture-recording technology in higher education: Exploring lecturer and student views across the disciplines
}

\author{
Kulari Lokuge Dona \\ Monash College \\ Janet Gregory \\ Swinburne University of Technology, Sarawak Campus \\ Ekaterina Pechenkina \\ Swinburne University of Technology
}

\begin{abstract}
This paper presents findings of an institutional case study investigating how students and lecturers experienced a new opt-out, fully integrated lecture-recording system which enabled audio and presentation screen capture. The study's focus is on how 'traditional' students (generally characterised as young, enrolled full-time and attending classes on campus) engaged with lecture-recording and how lecturers' experiences with, and attitudes towards, lecture-recording differed depending on their discipline. Students were generally positive about the affordances of the lecture-recording system, whilst lecturers remained undecided on its value. Discipline-based differences in lecturer engagement with the system were noted between lecturers teaching engineering and sciences subjects and those teaching business and social sciences, the latter being more positive towards the system. The paper raises questions about the efficacy of a one-size-fits-all lecture-recording system given differences in disciplinary activities, lecturer styles and approaches to teaching.
\end{abstract}

\section{Introduction}

Today, technological advances have a firm foothold in higher education, with the traditional mode of faceto-face delivery of lectures and tutorials embracing the affordances of technology (Kirkwood \& Price, 2014). In response to the growing demand from students for personalised learning (Shah, Sid Nair, \& Bennett, 2013; Wanner \& Palmer, 2015), lecture-recording technology has been adopted by universities to enable a shift from a one-size-fits-all education system towards one where students can personalise and customise their learning (Johnson, Adams Becker, Estrada, \& Freeman, 2015).

Lecture-recording systems are present in some shape or form across most Australian universities: Echo360 system is the most frequently used, with $57 \%$ of Australasian Council on Open, Distance and e-Learning (ACODE) member universities having this system implemented (ACODE, 2013). Echo360 is also widely distributed across institutions internationally (Echo360, 2015). Other systems of video-recording, though all different in method and purpose, include Camtasia Relay, Abode Captivate and Blackboard Collaborate.

Institutional initiatives in recording lectures have evolved from the delivery of tape recordings for distance students, supplied in addition to printed study materials, to delivery ranging from streaming to downloading to podcasting (Gosper et al., 2008). Lecture-recording practices also vary between universities: institutions may offer audio only; audio accompanied by presentation slides or videos; or a combination of video, audio and media files (Phillips et al., 2007). In addition, approaches to lecture-recording can be opt-in or opt-out (ACODE, 2013) meaning that lecturers can either opt in and request that their lectures be recorded, or be required to opt out when the system is set up automatically to record and upload lectures.

Lecture-recording in higher education has a distinctly different purpose from videos used to enable online learning. For example, content videos used in massive open online courses (MOOCs), or short videos introduced in various blended learning models, are generally scripted and concise with the intent of providing key information points on a topic. In contrast, lecture-recordings entail a digital capture of faceto-face lectures to be made available to students online (Woo et al., 2008) and, as such, are long - commonly one hour - and generally unscripted. 
Most contemporary lecture-recording systems work to enable access to the recording via a passwordprotected learning management system (LMS); but variations occur in the level of automation of the recording process as well as the levels of support and adoption. As such, studies that specifically compare one method of delivery over another for benefits and drawbacks are needed. Whilst there are institutional and cross-institutional case studies of the use of lecture-recording systems (Friedland, Knipping, Schulte, \& Tapia, 2004; Larkin, 2010; Phillips et al., 2007) as well as discipline- and cohort-specific studies (Johnston, Massa, \& Burne, 2013; Leadbeater, Shuttleworth, Couperthwaite, \& Nightingale, 2013; SpaethHilbert, Seufert, \& Wesner, 2013; Yeung, Raju, \& Sharma, 2016a), this paper addresses current knowledge gaps by presenting evidence of disciplinary differences amongst lecturers in their views about the use of lecture-recordings, and expanding on comparisons between student-lecturer experiences following the introduction of Echo360 as an opt-out system.

\section{Lecture-recording: Benefits and challenges}

The attitudes and goals of lecturers and students in regard to the use of educational technologies for learning and teaching can often be incompatible (Johnson et al., 2015; Phillips et al., 2007). Specifically, research into lecture-recording systems and their impact on learning and teaching processes presents a diverse and highly contested area of knowledge, where the interplay between the presence of lecture-recording, student decision-making around lecture attendance and lecturer attitudes towards lecture-recording is complex and still not very well understood.

Students generally report positive responses to lecture-recording and use the recordings to support their studies. Several studies (Kinash, Brand, \& Mathew, 2012; Maynor, Barrickman, Stamatakis, \& Elliott, 2013; Van Zanten, Somogyi, \& Curro, 2012) reported that students valued lecture-recordings and used them primarily to review the lecture material. Tarr et al. (2015) found that students appreciated the option to learn at their own pace, for example, by doing required reading immediately prior to listening to the recording of a lecture, hence maximising effective study time. Students also appreciated being able to pause the recording whenever their attention waned and using recordings to review material in preparation for assessments (Tarr et al., 2015). Utilising cost-benefit analysis, Taplin, Kerr, and Brown (2013) even concluded that students would be willing to pay a reasonable fee to download their lecture-recordings.

Studies focused on the perceptions of both students and lecturers tend to present mixed results. Price and Almpanis (2015) found both students and lecturers to be very positive about lecture-recording technology and its capacity to enhance student learning, especially in preparation for assessments. However, others (Larkin, 2010; Maynor et al., 2013; O’Callaghan, Neumann, Jones, \& Creed, 2015; Phillips et al., 2007) report on differing perceptions by students and lecturers, with students generally in favour of having immediate access to the recordings, and lecturers remaining undecided and concerned that students may watch a recording rather than attend a face-to-face lecture, which might cause their studies to suffer.

Concerns by lecturers that students may choose to miss classes due to lecture-recordings are not substantiated in the research. Maynor et al. (2013) found that only $10 \%$ of their sample of 140 students said they used recordings as a substitute for class; however, nearly half of the same sample said that hypothetically they would be more likely to miss a lecture if they knew it was being recorded. Similarly, in the Marchand, Pearson, and Albon (2014) study only 10\% of 210 participating students said they were using recordings as a substitute to attending a lecture. The same study (Marchand et al., 2014) found that lecturers did not notice any changes in students' overall academic performance but perceived increased absenteeism; while a study by Yeung, Raju, and Sharma (2016b) indicated that students who were nonfrequent lecture attendees were not likely to use lecture-recordings to make up for a missed a lecture compared to those who were frequent attendees. Further, a survey of over 500 students (Gysbers, Johnston, Hancock, \& Denyer, 2011) found that the majority of students always or mostly attended lectures even though lecture-recordings were available - students said they perceived lecture-recordings as not always reliable and as limited in the content they captured. The same study (Gysbers et al., 2011) found that when students did not attend lectures, this was due to a variety of logistical reasons, including inconvenience, overcrowded lecture rooms and peer distraction.

The findings from these studies suggest that the presence of lecture-recordings may not be the deciding factor in a student's decision not to go to class, as other factors may be more significant - students may miss face-to-face lectures for a variety of pragmatic, pedagogical and personal reasons, which have little or 
nothing to do with whether lectures are recorded or not. Among these reasons of non-attendance are sleeplessness, illness, the need to prioritise time and study for examination in other subjects instead of attending lectures and having other competing commitments; other factors such as poor weather conditions preventing students to travel to campus and perceived inefficiencies of lectures conducted in overcrowded lecture halls have also been found to be important factors for students when deciding whether to attend a lecture or not (Bati, Mandiracioglu, Orgun, \& Govsa, 2013).

A number of studies evaluating lecture-recording models and approaches have reported that lecturerecording tools play a significant role in enhancing students' educational experiences by making lectures more accessible and flexible (McNaught, Lam, Chan, Yuen, \& Ho, 2012; Secker, Bond, \& Grussendorf, 2010; Toppin, 2011; Woo et al., 2008). In their comprehensive review of lecture-recording research, Kinash et al. (2015) found no evidence to suggest students' achievement suffered when lecture-recordings were available. McKenzie (2008), who studied the effectiveness of lecture-recording as a learning tool, showed that, when compared to attending face-to-face lectures, listening to lecture-recordings was at least as effective in meeting students' learning objectives as rated by students themselves. Some studies specifically looked at how lecture-recording technologies support students from non-English-language backgrounds (Leadbeater et al., 2013; Pearce \& Scutter, 2010), and it was suggested that this group of students, as well as those with various disabilities (such as fatigue disorder or dyslexia), can benefit greatly from the lecturerecording opportunities (Claret, 2016).

In addition to student attendance patterns and the evaluation of effectiveness of lecture-recordings as a learning tool, the question of whether (and how) lecture-recording affects teaching constitutes a third important topic of scholarship in this area. In their review of lecture-recording scholarship, O'Callaghan et al. (2015) found that lecturers felt that the presence of lecture-recording restricted the structure of lectures. This result supports older studies that raised similar concerns around lecture-recording and lecturing styles. For instance, Donnan, Kiley, and McCormack (2004) found that some of the critique of lecture-recording by lecturers existed because lecturers felt lecture-recording placed rigid limitations on how lecturers taught. Phillips et al. (2007) confirmed that lecturers felt they had to adopt a more didactic style of lecturing to accommodate the presence of lecture-recording systems, and as a result they became more self-conscious about their teaching and their lectures lost an element of spontaneity.

In regards to how lecturers altered their teaching in response to the presence of lecture-recording technologies, Gosper et al. (2008) presented three key scenarios lecturers could adopt when engaging with lecture-recording technologies. In the first scenario, lecturers make no changes to the way they teach, choosing to maintain the status quo and reminding students that lecture attendance is important. In the second scenario, lecturers make an effort to accommodate technology. For instance, they reduce their movement in class, do not use copyrighted multimedia and adopt sound-inclusive practices, such as repeating questions asked from the audience and speaking more slowly. In addition, lecturers in this scenario tend to script their lectures more tightly and utilise online discussion boards and other communication mediums in an attempt to make their content more inclusive. Finally, in the third scenario, lecturers make an effort to redesign curriculum with the intent to allow more time for interactive situations in class by replacing face-to-face components with lecture-recording, hence leaving more time for engaged discussions, hands-on activities and other practical components of the learning process. After reviewing lecture-recording scholarship, Kinash, Knight, and McLean (2015) argued that delivery of content via recorded lectures has the capacity to influence a shift from didactic lecture towards more constructivist learning.

We were interested to explore whether changes in teaching approaches due to lecture-recording varied across disciplines - specifically the disciplines of science, business and social sciences - as we found no studies that addressed this question. Consequently, this case study, following the institutional implementation of Echo360 lecture-recording opt-out system, aimed to understand how the new system was received by its end users - students and lecturers - and specifically whether there were major differences in lecturer perceptions and approaches across disciplines. In particular, we wanted to establish how students and lecturers engaged with this new system; how they used its affordances; and what were its key benefits and drawbacks. Analysis of the experiences and perceptions of Echo360 opt-out system by students and lecturers has enabled us to investigate major interdisciplinary differences between lecturers as well as compare student and lecturer experiences. In the sections that follow we set out the case of lecturerecording at our university, describe our method and sampling and discuss our findings. This research 
followed the structure of a case study design where lecturers and student perspectives were contextualised in our institutional environment. Further, by combining qualitative and qualitative components in lecturer and student surveys, we were able to validate our data by combining two types of data and triangulating the responses.

\section{The case study}

Our university adopted a fully automated system Echo360 in 2014. In addition to being fully automated, the system was integrated with the timetabling system and the university's LMS requiring lecturers to opt out if they did not want lectures recorded. The system's opt-out aspect meant that all lectures scheduled in Echo360-equipped rooms would automatically be recorded and transferred to the LMS for students to access almost instantly. The system was designed to avoid additional manual processing: lecturers did not have to manually request, upload or make recordings available to students as this was all managed automatically. It is important to note at this point that whilst this system was an opt-out system, and all recordings were automatically made available to students, lecturers did have the option of pausing the recording, editing the recording and even deleting it from the LMS. Lecturers were trained on how to implement these steps, when appropriate, giving lecturers control over the availability and accessibility of their lecture materials.

We selected a case study methodology as the case study is a particularly useful method when doing evaluation research and exploring an area where there is limited knowledge. Our goal was to evaluate the new lecture-recording system by drawing on data of the experiences of lecturers and students across different disciplines to build on existing knowledge and to explore whether differences existed between disciplines following the introduction of this new opt-out lecture-recording system. A case study methodology enabled a holistic perspective of the experiences of both participant groups as a complex phenomenon (Patton, 2002a, 2002b). It also allowed for the presentation of evidence which could support other institutions using opt-out lecture-recording systems across different discipline groups in understanding this experience and developing their own conclusions (Stake, 2000). The case study drew on a combination of qualitative and quantitative data collection methods, all positioned within the context of our institutional environment.

Data was gathered through surveys with both students and lecturers and interviews with technical staff responsible for the implementation and functions of Echo360. The surveys had quantitative and qualitative components, allowing for both depth and breadth of data. The surveys were fully anonymous and hosted online by the Opinio platform. They combined Likert-scale and yes/no questions, opinion rubrics and openended write-in questions intended to generate qualitative data. When analysing the survey data we have drawn on the mixed method approach (Bazeley, 2009, 2013; Creswell, 2003), which allowed us to combine analysis of quantitative and qualitative data and draw conclusions.

The student survey contained 32 questions and was distributed to a sample of students who were enrolled in lecture-recording-enabled units in semester 2, 2014. As per approved ethics protocols, student emails were extracted from the LMS and randomised. The fully anonymous survey was open for the period of one month, during which time 66 valid responses were recorded. Mixed-method analytical software Dedoose was used to analyse qualitative data from both surveys and draw trends from open-ended response data. The lecturer survey, comprising 14 questions, received 53 valid responses. In addition to questions related to lecture-recording, the student survey also collected general demographic information, including data on gender, age and discipline of study. This allowed us to position our student participant cohort within the university's general student population: according to 2014 full-year statistics (Department of Education and Training), over $65 \%$ of our university's total student population were attending classes on campus, 63\% were enrolled in a full-time mode and the gender split was near equal. Furthermore, the majority of all students in that year (75\%) were domestic students. All percentages presented throughout findings section are rounded up and only key trends are reported.

The self-selecting nature of our participant cohorts meant that only those participants who had experienced the lecture-recording system and wanted to share their opinions about it responded to the surveys. Seven semi-structured interviews conducted in parallel to the surveys elicited in-depth experiences of staff members who were in charge of implementing and trialling the new Echo360 system - and while we do not specifically report on the interview findings here, nonetheless, this data allowed us to clarify the context 
of Echo360's implementation at our university. The anonymous nature of the mixed-methods survey allowed both lecturers and students to speak freely and determine the topics of importance to them (by answering open-ended questions) in relation to our inquiry. The case study approach was appropriate in this study as our main research questions were around how students and lecturers were engaging with the new lecture-recording system and why. The research team had little control over behavioural events, and the focus of our study was contemporary; that is, it was occurring in real time as we were conducting this study (Yin, 2013).

In this exploratory study, we accepted the small sample size (a total of 119 participants) as we were building on other studies into lecture-recording while contributing to a new area of scholarship - that of interdisciplinary differences in experiences with lecture-recordings. While we realise our research findings cannot be generalised to lecturer and student experiences with lecture-recording in other universities, interpretations we make on the basis of our rich data can inform and provide insights for other universities using lecture-recording systems.

\section{Findings: Student and lecturer experiences with lecture-recording}

\section{Students}

Student demographics data indicate that $37 \%$ were in the age bracket of $21-25$, followed by those aged 1820 (20\%), with mature-aged students in their thirties forming the third largest age sub-group (15\%) and the rest of students (18\%) spread across smaller age groups. The gender split in this sample was close to 50/50. The largest group in the sample was either in their second year of study (36\%) or in their third (33\%); with only a few being first-year (6\%) or fourth-year and beyond students. Most students were from the Faculty of Science and Engineering (43\%), followed by those from the Faculty of Business and Law (37\%), with a small group (9\%) from Arts and Social Sciences. Throughout the paper, we will refer to these three discipline-specific groups as ‘sciences’, 'business’ and ‘arts’ respectively.

Most students in our sample (77\%) were domestic, and 14\% were international (the remaining 9\% either skipped this question or responded 'other'). The majority of student respondents were not employed (42\%), with 21\% employed in jobs requiring 11-20 hours of engagement a week, 15\% working 6-10 hours a week and the remaining $22 \%$ engaged in 'other' types of employment. Corresponding to the fact that only a small percentage of students in our sample had full-time jobs (8\%), most of them were enrolled on a full-time basis (70\%); the biggest segment of population were enrolled in an undergraduate degree (79\%) and studying all subjects on campus. The general picture these statistics paint is of a predominantly 'traditional' student body: younger students who are not employed full-time and who attend most of their classes in a face-to-face mode on campus.

When asked how many of their enrolled units of study were supplemented with lecture-recording feature, $46 \%$ of student respondents indicated at least some units had this feature, and $31 \%$ had all of their units equipped with lecture-recording. A very small number of participants either had no recordings of their lectures available or were not aware if there was such an option. Nearly all student respondents accessed and utilised lecture-recordings at least once per month; however, 31\% reported their usage pattern encompassed multiple access times per week.

The most frequent responses from students regarding how they used lecture-recordings were:

- to revisit and clarify complicated or confusing topics

- $\quad$ to prepare for exams

- to learn at my own pace

- $\quad$ to improve overall learning experience

- $\quad$ to help balance schedule (including studies, family and work).

These trends support findings from many other studies, profiled earlier, where students mainly used lecturerecordings to catch up and revise. Furthermore, our study found that students valued lecture-recordings as the recordings eliminated a great deal of stress from their lives by allowing them 24/7 access to lectures, as the quote below illustrates: 
Recordings allow me to revisit the lecture notes and write down notes I may have misheard or missed during the lecture as there is a lot of content. Also you don't want to disturb the flow of the lecture with constant questions that will possibly not allow the whole class to get through all of the available content.

Another student responded: '[I appreciate] the ability to view [lectures] at my own time, when I am attentive and engaged. Often in class I may not take in all the information, and reviewing it greatly helps fill gaps in my knowledge.' Overall, personalised learning emerged as a key theme with students: they perceived lecture-recordings as enabling a more effective usage of time and the achievement of higher grades. A significant group of students (18\%) even credited lecture-recording with helping them stay in a class stating that otherwise they would have dropped out. However, there were also those (35\%) who stated that they used lecture-recordings as a substitute for attending class - an item of concern for many lecturers, as previous studies showed. No clarification was given from this group of students as to why they relied on lecture-recordings and skipped lectures - this matter could form the basis of future studies of contemporary student experiences, especially considering most students in our sample were not employed full-time and therefore had to have reasons other than work not to come to lectures.

A very small group of students (4\%) appreciated lecture-recording availability stating that because their first language was not English they used recordings to better understand lecture content and improve their comprehension. Some students commented that lecture-recordings helped them understand lecturers with strong accents. Overall, 71\% of students surveyed in this study believed that access to lecture-recordings benefited them in their learning, and a majority (nearly 70\%) would like to see recordings offered in more of their units of study, wishing for a more uniform approach to lecture-recording offerings at an institutional level.

The evidence of student engagement with lecture-recordings in this study supports the findings from other studies showing students' positive perceptions of lecture-recording. Students across all disciplines in our study indicated that they used lecture-recording to review, revise or catch up on missed lectures, and, regardless of their discipline, students wanted lecture-recording to be available across all their subjects believing recordings enhanced their studies.

\section{Lecturers}

The lecturers who participated in this survey came from three key discipline groupings: 45\% were from sciences and engineering disciplines; 36\% from business and law; and 17\% from arts and social sciences. Overall, $70 \%$ of participating lecturers were teaching face-to face, with $26 \%$ teaching in blended mode, and the remaining few teaching fully online. In contrast to the student responses, where the majority of students replied they would like to have lecture-recording option available in more units, only $28 \%$ of all lecturers answered affirmatively, with the majority of them stating they did not want their lectures recorded in the future at all.

In this study, we wanted to address the question of lecturer engagement with, and perception of, lecturerecording across different disciplines. In particular, with the almost equal split between participants coming from sciences and those from business, this study presented an interesting case for cross-disciplinary comparisons. It is interesting to note here that the mode of teaching also varied across disciplines, with $91 \%$ of sciences lecturers stating that they teach predominantly in face-to-face mode compared to $63 \%$ lecturers from business and $44 \%$ from arts. This raises questions about disciplinary differences in approaches to teaching and/or different perceptions of the meaning of terms such as 'blended delivery'. The rest of this section reports on findings around similarities and differences between lecturers' engagement with lecturerecording system depending on which discipline they came from. The main points of comparisons are between perceived benefits and limitations of the system; and the effect of lecture-recording on various aspects of teaching and academic performance.

Trends of engagement across three broad disciplines: Benefits and limitations

Sciences lecturers perceived the main benefit of lecture-recording as the opportunity it provided students to review and revise lecture materials. Despite that, the perception within this discipline group was that 
students who use lecture-recording feature are already high-achieving students who are strongly motivated to do well in their studies, with or without this technology. As one participant stated:

[Recordings of lectures] are very helpful for the high-end students (that don't necessarily need it!) but either aren't used or are 'crammed' by the students that do need it. A few students have verbally confirmed this with me. I've had conversations with dedicated students who loathe watching them when they miss a lecture. As someone trying to promote good study habits, I find that for the most part, it seems to do the opposite.

The primary concern articulated here is that students who were not highly motivated might be tempted to listen to recordings instead of attending lectures, with one respondent commenting:

[The presence of lecture-recording] gives the perception that students can skip class and catch up which I strongly doubt they do, given the viewing statistics. It may even impact on other units - as not turning up for a class can escalate to not turning up to university for that day.

A main concern for this group of lecturers was that the system was limited in what it could capture: 'because Echo does not capture whiteboard, most students find it useless and prefer visiting me in my office for consultation anyway'. Another lecturer in this group also felt that the benefit of lecture-recording in its current form was 'marginal' to students, also explaining it by the system's limitations: 'Echoes provide slides (which the students already have access to) and audio. Student use was limited to a few exploratory listens. Very few students actually used the echoes'. Furthermore, engineering and sciences lecturers were concerned that having the option of lecture-recording was creating a 'disconnect with the students', making their students more disengaged and isolated to the point it became more difficult for the lecturers 'to identify ways in which to help the students'.

Business lecturers also perceived the main benefit of lecture-recording as the opportunity for students to catch up, revise and review, particularly for those who could not physically attend the lecture, stressing it enabled students to listen to the discussions and questions associated with missed lectures rather than just reading lecture-materials. Interestingly, in this group of lecturers, even those who did not see any direct benefit of the system for themselves as academics acknowledged it may be useful to students. One participant commented that lecture-recording 'allowed students to revise lectures and, when absent, to catch up on missed lectures', while another affirmed that lecture-recording provided 'students with a learning resource that does not depend on real time attendance or real time lecturer explanations'.

There were also concerns amongst business lecturers with some considering lecture-recording options as a 'very big disincentive for students turning up to lectures', believing students were tempted to rely on lecture-recordings and 'play 'catch-up' at the end of the semester'. Another lecturer in this group suspected that if students chose not to turn up for a lecture, they were not listening to lecture-recordings either: based on the viewing statistics only about $50 \%$ of students in this lecturer's class downloaded lecture-recordings and overall 'there was little [viewing statistics] activity during the semester'. Finally, another lecturer felt that students did not access lecture-recordings because of the typical length of the recordings: 'it's still an hour to listen to!' This lecturer concluded that 'recording the lecture is not enough - [recordings] need editing, ability to allow for breaks and clearly able to identify sections that students may need to access not just the whole lecture.'

The third (and the smallest) cohort of lecturers in this study, those in the arts and social sciences, also highlighted the revision and review option as the main benefit of lecture-recording for their students. However, they also appreciated 'the potential [of lecture-recording] to reach more students', for instance, by being 'able to record the workshops for distance students' and to 'reuse the recording across teaching periods with other students.' Arts lecturers also appreciated the 'ease of use' of the opt-out system such as the fact that they didn't 'have to apply for it anymore as it records automatically'. In contrast, the sciences lecturers did not comment on the ease of the new system; their comments were focused on the way the system affected their teaching.

Effects of lecture-recording on student academic performance

Lecturers across the disciplines expressed quite different perceptions about the effects of lecture-recording on their students' academic performance. $12 \%$ of sciences lecturers noticed a major reduction in academic 
performance in their class, and another $12 \%$ noticed a slight reduction in academic performance. In contrast, $53 \%$ of business lecturers and 55\% of arts lecturers did not notice any change to their students' academic performance. The question of whether these perceptions actually indicate changes in academic performance, and whether or not there are differences across disciplines, is an area that requires further evidence-based research as any changes to academic performance due to lecture-recording need to be well documented, understood and the implications managed.

\section{Effects of lecture-recording on teaching}

Lecturers were asked whether they had made any changes to the way they taught in order to fully leverage the presence of lecture-recording. $67 \%$ of sciences lecturers and $68 \%$ of business lecturers said they did not implement any changes, whereas arts lecturers were evenly split between those who changed the way they taught and those who did not.

One significant issue raised by sciences lecturers was the concern that their discipline area is incompatible with lecture-recording. They specified issues including that 'physical models [could not] be used to demonstrate abstract concepts' and that the system '[did] not capture real-time handwriting on the board which [was] the most fundamental and academically proven form of delivering quantitative and rigorous material'.

A lecturer from the business cohort commented that lecture-recording had a negative effect on his teaching due to copyright restrictions and raised levels of self-consciousness:

I believe that I am far more reserved in lectures. I am far less likely to provide specific examples for students (such as providing business/brand names), which means that the students come away with less understanding of the concepts than they otherwise would. The recording of the lectures has made me far more self-conscious. I feel that every error I make (such as any mispronunciation) is amplified. As a result of feeling more self-conscious, I feel that my lectures are more boring and less engaging than they used to be before the lectures were recorded.

Another lecturer from the same cohort, however, took advantage of lecture-recording affordances in an innovative way:

I do not give a 'lecture' as such. I use Echo360 to capture my own instructions to students (how to do things), and to pre-record lectures that my students are instructed to watch in their own time. This is useful because it is organised, uninterrupted, can be accessed by students in their own time - and is just the 'lecture' not any extraneous 'stuff' they have to wade through to get to the 'lecture'.

A small group of sciences lecturer also felt there was a potential for lecture-recording to be used in future semesters to enable students' independent study while the scheduled lectures' content could be 'flipped' and made more hands-on and interactive. Lecturers, in all disciplines, were exploring alternative models of leveraging technology to provide material for students, with some hoping that this may also enhance their own experience by enabling them to 'gain at least some additional time in future semesters now that an entire semester of lectures has been recorded'.

\section{Discussion and conclusions}

This study analysed the differences between lecturers and students' perceptions of, and experiences with, an opt-out approach to lecture-recording using Echo360 in an Australian university. By illuminating variations in lecturers' engagement with lecture-recording across broad disciplinary groupings, our study has expanded on previously published research concerned with the differences in how lecture-recording is perceived by students and lecturers (Larkin, 2010; Maynor et al., 2013; O’Callaghan et al., 2015). In our institution, the main goal behind Echo360 opt-out system implementation was to provide greater flexibility for students to learn wherever and whenever it suited them, and to increase accessibility to lecture materials - including the option to review and revise recordings of live lectures. The opt-out system was received well by most lecturers, and the seamless technology, with immediate upload of lecture materials, enabled easy access for students. Overall, lecturers believed that the group of students who benefited most from 
lecture-recordings were those students who were already highly motivated, enthusiastic and high achieving - a group that would do well regardless. This resonates well with studies such as Yeung et al. (2016b), which found that students who were non-frequent lecture attendees were also not likely to use lecturerecordings to make up for a missed a lecture, compared to those who were frequent attendees. Our finding in this regard builds on the existing body of scholarship indicating a variety of reasons behind students' choosing to skip a lecture, regardless of the availability of the lecture-recording.

In our study, lecturers generally perceived students as using lecture-recordings to supplement their learning, rather than as a replacement; however there were still concerns that lecture-recordings may encourage students to miss classes. Students, on the other hand, were generally positive about lecture-recordings and used them for a variety of reasons including review and revision which is consistent with many other studies (Maynor et al., 2013; Tarr et al., 2015; Van Zanten et al., 2012). The concern expressed by lecturers does appear to be supported by the number of students (35\% of our student sample) in this study agreeing that they used recordings instead of attending class (business and law students were slightly more likely to be in this group, with 52\% of them choosing this response compared to sciences and engineering students and arts and social sciences students, with $26 \%$ and $29 \%$ of each sub-group choosing this reply respectively). Overall, this segment of our entire student sample was three times higher than those reported in other studies (with bigger samples) (Marchand et al., 2014; Maynor et al., 2013). One of the limitations of our study, however, was that students were not asked to explain when, why and how they used recordings instead of attending class, leaving us to speculate about the potential for conflicting commitments and/or lack of interest. The question of when, why and how students use recordings, rather than attending classes, urgently requires further research.

The analysis of our cross-disciplinary survey data shows that lecturers from each of the three disciplines studied shared a perception that lecture-recording was useful for students to review, revise and catch up on missed lectures. However, results point to variations across disciplines in how willing lecturers were to change their teaching practice to align with lecture-recording. As discussed by Gosper et al. (2008), lecturers respond in different ways to lecture-recording and lecturers who took part in our study confirmed this finding. Responses ranged from those who did not want to change any aspect of their teaching approach to those who embraced the opportunity to teach differently. In our study, lecturers in the science discipline were most concerned about changing their teaching styles and were significantly more concerned with the system's limitations in terms of what could be captured in the recordings.

Further research is required to determine the reasons; however, we suggest that the concerns of lecturers in the sciences discipline point to limitations of the system and the current generation of lecture-recording systems. Science subjects require more in-class demonstrations, use of physical models and utilisation of whiteboards to demonstrate equations and formulae to students, compared to some other disciplines. It is therefore understandable that the current lecture-recording system may be perceived as not addressing the disciplinary specific requirements, as the system only captures the audio component and the PowerPoint screen. Equally, it could suggest that more information, resources and exemplars are needed to empower lecturers to take full advantage of lecture-recording, as lecturers may not be aware of ways to utilise the available educational technology or simply may not have any time to learn new ways of doing things.

Our findings indicate that the current lecture-recording system used by the university may be perceived as being more beneficial to some disciplines than others. To take full advantage of lecture-recording, some additional features may need to be introduced, for example, the interactive capabilities located within the recording such as the ability to add in-video quiz options to engage students. Further research is needed into how the lecture-recording system can cater for different disciplines and their preferred styles of teaching, particularly as universities move away from a didactic approach towards a more personalised learning mode of education delivery. The way a new system is implemented may be of great importance too - for example, training and sharing of good practice with lecturers could go a long way to enable them to use the system to best advantage.

It may be that the next generation of lecture-recording - equipped with a number of extra features such as wearable technologies, roaming camera options, personalised digital notes tool, downloadable digital whiteboards and in-built interactivity tools like online polling and quizzing - may better enable lecturers to mix and match models of recording that work best for their discipline and approach. The Active Learning Platfom, the latest version of Echo360 Lecture Capture and similar systems such as Panopto provide several 
new features that could address many of the discipline-specfic concerns expressed by our participants. Features such as real-time polling and quizzes, open-ended and image-based questions, live video streaming and document cameras to record handwritten notes and equations will take lecture-recording to the next level of technology-enabled learning. These new features will provide lecturers with more options and control and enable them to personalise their use of the technology to suit their discipline and teaching approach. This may then enable a personalised learning experience not only for students, but also for lecturers, and future research will demonstrate whether this changes the perceptions of lecturers towards lecture-recording.

In the meantime, further research may assist in understanding how and why students use and like lecturerecordings, as well as how lecture-recordings can be best utilised to enable and encourage lecturers to actively take on and use this technology to enhance their teaching. Clearly, from this study, the use of a seamlessly integrated opt-out model is one step towards making lecture-recording more appealing to lecturers (as well as students); however, other issues such as the impact on teaching style and the appropriateness for different disciplines warrant further exploration.

In conclusion, we suggest that, regardless of the approach taken by an institution, lecture-recording enables students to personalise their learning by allowing them to supplement (or replace) their face-to-face lectures; to study and revise differently for exams; to take fewer notes and to focus on listening during lectures knowing they can revisit the difficult parts of the lecture in their own time. Potentially, it reduces attendance at lectures; however, it is not clear whether lecture-recording alone is the cause of decreasing attendance, and further research is needed to ascertain the factors affecting attendance. Whilst lecturerecording does provide greater flexibility and personalise the experience for students, it has the potential to do the opposite for lecturers, particularly for those whose teaching approach or subject material does not lend itself readily to current models of recording of audio and PowerPoint slides.

One of the challenges is recognising the requirements of different disciplines, and the variation in lecture approach by individual lecturers, to consider whether an unintended consequence of lecture-recording is the creation of a more didactic and one-size-fits-all model of lecturing. The developments occurring within the lecture-recording technologies will enable lecturers to find different ways of recording, thereby making it possible for lecturers to tailor or personalise their approach. It is possible, of course, that even better recording options may further decrease student attendance at lectures and further research will be needed to determine the effect of lecture-recording on learning outcomes. The challenge for the users of the new lecture-recording technologies - the lecturers and students - will be addressing the implications of increasing opportunities for tailored and personalised learning for effective student learning.

\section{Ethics statement}

This research project received ethical clearance from the university's Human Research Ethics Committee and follows the Australian Government's National Statement on Ethical Conduct in Human Research (2007). Any conflicts of interest were minimal and resolved by employing a researcher who was not involved in the implementation of Echo360 opt-out system. All data used in this study was automatically de-identified to ensure the confidentiality and privacy of participants. To access the de-identified data used in this study, please email the corresponding author and provide a statement regarding the purposes of your request.

\section{References}

Australasian Council on Open, Distance and e-Learning. (2013). Lecture capture in Australasian universities. Retrieved from http://www.acode.edu.au/pluginfile.php/419/mod resource/content/1/ACODE Lecture Capture Report 2013.pdf

Bati, A. H., Mandiracioglu, A., Orgun, F., \& Govsa, F. (2013). Why do students miss lectures? A study of lecture attendance amongst students of health science. Nurse Education Today, 33(6), 596-601. doi:10.1016/j.nedt.2012.07.010

Bazeley, P. (2009). Analysing qualitative data: More than 'identifying themes'. Malaysian Journal of Qualitative Research, 2(2), 6-22. Retrieved from http://www.researchsupport.com.au/bazeley_mjqr_2009.pdf 
Bazeley, P. (2013). Qualitative data analysis: Practical strategies. Los Angeles, CA: Sage.

Claret, P. M. R. (2016, February). Lecture capture system for inclusive higher education. Paper presented at the National Conference on Higher Education in the Knowledge Age: Techno-Pedagogical Perspectives and Innovations, Tiruchirappalli. Retrieved from http://www.sjctni.edu/IQAC/NCHEKA.pdf

Creswell, J. W. (2003). Research design: Qualitative, quantitative and mixed methods approaches. Thousand Oaks, CA: Sage.

Department of Education and Training. (2014). Selected higher education statistics - 2014 student data. Retrieved from https://www.education.gov.au/selected-higher-education-statistics-2014-student-data

Donnan, P., Kiley, M., \& McCormack, C. (2004, November). Lecture streaming: Getting the pedagogy right. Paper presented at the Online Learning and Teaching Conference: Exploring Integrated Learning Environments, Brisbane . Retrieved from http://trove.nla.gov.au/work/153086251?q\&versionId=174617597

Echo360. (2015). Over 600 institutions and counting. Retrieved from http://echo360.com/clients

Friedland, G., Knipping, L., Schulte, J., \& Tapia, E. (2004). E-chalk: A lecture recording system using the chalkboard metaphor. Interactive Technology and Smart Education, 1(1), 9-20. doi:10.1108/17415650480000008

Gosper, M., Green, D., McNeill, M., Phillips, R., Preston, G., \& Woo, K. (2008). The impact of webbased lecture technologies on current and future practices in learning and teaching. Sydney: Australian Learning and Teaching Council. Retrieved from https://core.ac.uk/download/files/343/11242562.pdf

Gysbers, V., Johnston, J., Hancock, D., \& Denyer, G. (2011). Why do students still bother coming to lectures, when everything is available online? International Journal of Innovation in Science and Mathematics Education, 19(2). Retrieved from http://openjournals.library.usyd.edu.au/index.php/CAL/article/view/4887

Johnson, L., Adams Becker, S., Estrada, V., \& Freeman, A. (2015). NMC Horizon Report: Higher education edition. Austin, TX: The New Media Consortium. Retrieved from http://cdn.nmc.org/media/2015-nmc-horizon-report-HE-EN.pdf

Johnston, A. N., Massa, H., \& Burne, T. H. (2013). Digital lecture recording: A cautionary tale. Nurse Education in Practice, 13(1), 40-47. doi:10.1016/j.nepr.2012.07.004

Kinash, S., Brand, J., \& Mathew, T. (2012). Challenging mobile learning discourse through research: Student perceptions of Blackboard Mobile Learn and iPads. Australasian Journal of Educational Technology, 28(4), 639-655. doi:10.14742/ajet.832

Kinash, S., Knight, D., \& McLean, M. (2015). Does digital scholarship through online lectures affect student learning? Educational Technology \& Society, 18(2), 129-139. doi:10.3991/ijet.v512.1166

Kirkwood, A., \& Price, L. (2014). Technology-enhanced learning and teaching in higher education: What is 'enhanced' and how do we know? A critical literature review. Learning, Media and Technology, 39(1). doi:10.1080/17439884.2013.770404

Larkin, H. E. (2010). "But they won't come to lectures...” The impact of audio recorded lectures on student experience and attendance. Australasian Journal of Educational Technology, 26(2). doi:10.14742/ajet.v26i2.1093

Leadbeater, W., Shuttleworth, T., Couperthwaite, J., \& Nightingale, K. P. (2013). Evaluating the use and impact of lecture recording in undergraduates: Evidence for distinct approaches by different groups of students. Computers \& Education, 61, 185-192. doi:10.1016/j.compedu.2012.09.011

Marchand, J.-P., Pearson, M. L., \& Albon, S. P. (2014). Student and faculty member perspectives on lecture capture in pharmacy education. American Journal of Pharmaceutical Education, 78(4), 1-7. doi:10.5688/ajpe78474

Maynor, L. M., Barrickman, A. L., Stamatakis, M. K., \& Elliott, D. P. (2013). Student and faculty perceptions of lecture recording in a doctor of pharmacy curriculum. American Journal of Pharmaceutical Education, 77(8), 1-7. doi:10.5688/ajpe778165

McNaught, C., Lam, P., Chan, E., Yuen, S., \& Ho, E. (2012). Cultural aspects of adoption of innovation: A case study with implementing a lecture-recording system in a university in Hong Kong. Journal of the NUS Teaching Academy, 2(2), 95-108. Retrieved from http://www.nus.edu.sg/teachingacademy/article/cultural-aspects-of-adoption-of-innovation-a-casestudy-with-implementing-a-lecture-recording-system-in-a-university-in-hong-kong/

O’Callaghan, F. V., Neumann, D. L., Jones, L., \& Creed, P. A. (2015). The use of lecture recordings in higher education: A review of institutional, student, and lecturer issues. Education and Information Technologies, 1-17. doi:10.1007/s10639-015-9451-z 
Patton, M. Q. (2002a). Qualitative evaluation and research methods. Thousand Oaks, CA: Sage.

Patton, M. Q. (2002b). Two decades of developments in qualitative inquiry a personal, experiential perspective. Qualitative Social Work, 1(3), 261-283. doi:10.1177/1473325002001003636

Pearce, K., \& Scutter, S. (2010). Podcasting of health sciences lectures: Benefits for students from a nonEnglish speaking background. Australasian Journal of Educational Technology, 26(7), 1028-1041. doi:10.14742/ajet.v26i7.1032

Phillips, R., Gosper, M., McNeill, M., Woo, K., Preston, G., \& Green, D. (2007, December). Staff and student perspectives on web-based lecture technologies: Insights into the great divide. In ICT: Providing choices for learners and learning. Proceedings of ascilite Singapore 2007 (pp. 854-864). Retrieved from http://www.ascilite.org/conferences/singapore07/procs/phillips.pdf

Price, D., \& Almpanis, T. (2015). Student and staff perceptions on the impact of lecture capture. In Proceedings of the International Conference on Information Communication Technologies (pp. 215225). Retrieved from http://www.icicte.org/ICICTE2015Proceedings(Papers)/6.2\%20Fin\%20124_Price\%20\%20Almpanis \%20edit\%203\%20-last.pdf

Secker, J., Bond, S., \& Grussendorf, S. (2010, September). Lecture capture: Rich and strange, or a dark art? Paper presented at the ALT-C, Nottingham. Retrieved from http://eprints.lse.ac.uk/29184/2/Lecture_capture_(LSERO_version).pdf

Shah, M., Sid Nair, C., \& Bennett, L. (2013). Factors influencing student choice to study at private higher education institutions. Quality Assurance in Education, 21(4), 402-416. doi:10.1108/QAE-04-2012-0019

Spaeth-Hilbert, T., Seufert, T., \& Wesner, S. (2013). Lecture-Recordings: A solution for students of psychology as a minor subject? Journal of e-Learning and Knowledge Society, 9(2), 115-127. Retrieved from http://www.je-lks.org/ojs/index.php/Je-LKS_EN/article/download/836/824

Stake, R. (2000). Case studies. In N. Denzin \& Y. Lincoln (Eds.), Handbook of qualitative research (pp. 435-455). Thousand Oaks, CA: Sage

Taplin, R. H., Kerr, R., \& Brown, A. M. (2013). Who pays for blended learning? A cost-benefit analysis. The Internet and Higher Education, 18, 61-68. doi:10.1016/j.iheduc.2012.09.002

Tarr, J., Farrington, S., Pittaway, J., Bird, M.-L., Hoffman, K., Douglas, T., \& Beh, C.-L. (2015, July). Challenges for this place or any place: Student preferences for lecture 'places' in a blended learning environment. Paper presented at the 38th HERDSA Annual International Conference, Melbourne. Retrieved from http://herdsa.org.au/publications/conference-proceedings/research-and-developmenthigher-education-learning-life-and-38

Toppin, I. N. (2011). Video lecture capture (VLC) system: A comparison of student versus faculty perceptions. Education and Information Technologies, 16(4), 383-393. doi:10.1007/s10639-010-9140-x

Van Zanten, R., Somogyi, S., \& Curro, G. (2012). Purpose and preference in educational podcasting. British Journal of Educational Technology, 43(1), 130-138. doi:10.1111/j.1467-8535.2010.01153.x

Wanner, T., \& Palmer, E. (2015). Personalising learning: Exploring student and teacher perceptions about flexible learning and assessment in a flipped university course. Computers \& Education, 88, 354-369. doi:10.1016/j.compedu.2015.07.008

Woo, K., Gosper, M., McNeill, M., Preston, G., Green, D., \& Phillips, R. (2008). Web-based lecture technologies: blurring the boundaries between face-to-face and distance learning. Research in Learning Technology, 16(2), 81-93. doi:10.1080/09687769.2010.529111

Yeung, A., Raju, S., \& Sharma, M. D. (2016a, September). Investigating student preferences of online lecture recordings and lecture attendance in a large first year psychology course. Paper presented at The Australian Conference on Science and Mathematics Education, University of Sydney.

Yeung, A., Raju, S., \& Sharma, M. D. (2016b). Online lecture recordings and lecture attendance: Investigating student preferences in a large first year psychology course. Journal of Learning Design, 9(1), 55-71. Retrieved from https://www.jld.edu.au/article/view/243

Yin, R. K. (2013). Case study research: Design and methods: Los Angeles, CA: Sage.

Corresponding author: Ekaterina Pechenkina, epechenkina@swin.edu.au

Australasian Journal of Educational Technology @ 2017.

Please cite as: Lokuge Dona, K., Gregory, J., \& Pechenkina, E. (2017). Lecture-recording technology in higher education: Exploring lecturer and student views across the disciplines. Australasian Journal of Educational Technology, 33(4), 122-133. https://doi.org/10.14742/ajet.3068 